\title{
Stroke Education in Canadian Emergency Medicine Residency Programs
}

\author{
Devin R. Harris, MD, MHSc**; Philip Teal, $\mathrm{MD}^{\ddagger}$; Matthew Turton, $\mathrm{MD}^{\S}$; Brian Lahiffe, $\mathrm{MD}^{\dagger} \|$; \\ Simon Pulfrey, $\mathrm{MD}^{\dagger} \|$
}

\section{ABSTRACT}

Objectives: Stroke and transient ischemic attack (TIA) are common disorders treated by Canadian emergency physicians. The diagnosis and management of these conditions is timesensitive and complex, requiring that emergency physicians have adequate training. This study sought to determine the extent of stroke and TIA training in Canadian emergency medicine residency programs.

Methods: A two-page survey was emailed to directors of all English-speaking emergency medicine residency programs in Canada. This included both the Fellow of the Royal College of Physicians of Canada (FRCPC) and the College of Family Physicians Enhanced Training [CCFP(EM)] residency programs. The number of mandatory and elective rotations, lectures, and examinations relevant to stroke and TIA were assessed.

Results: Nine FRCPC programs responded (of $11 ; \mathrm{RR}=82 \%$ ) and $11 \operatorname{CCFP}(E M)$ programs responded (of 18; $R R=61 \%$ ), representing 20 of 29 programs in Canada (RR: 20/29 =69\%). Mandatory general neurology (3/9) and stroke neurology (2/9) rotations were offered in a minority of FRCPC programs and not at all in $\operatorname{CCFP}(E M)$ programs (0/11). Neuroradiology rotations were mandatory in 1/9 FRCPC programs and no CCFP(EM) programs (0/11). Acute ischemic stroke was allocated 3 hours of lecture time per year in all residency programs, regardless of route of training. Despite the fact that $100 \%$ of respondents train residents in facilities that administer thrombolysis for stroke, only $1 / 11$ (9\%) CCFP(EM) programs and 0/9 FRCPC programs have residents act as stroke team leaders.

Conclusions: Formal training in stroke and TIA is limited in Canadian emergency medicine residency programs. Enhanced training opportunities should be developed as this disease is sudden, life-threatening, and can have disabling or fatal consequences, and therapeutic options are time sensitive.

\section{RÉSUMÉ}

Objectif: Les accidents vasculaires cérébraux (AVC) et les accidents ischémiques transitoires (AIT) sont des troubles souvent traités dans les services des urgences au Canada. La pose du diagnostic et la prise en charge de ces affections sont complexes et le temps est un facteur important, aussi les urgentologues doivent-ils avoir une formation adéquate. L'étude visait justement à déterminer la place qu'occupe la formation sur les AVC et les AIT dans les programmes de résidence en médecine d'urgence au Canada.

Méthode: Un questionnaire de deux pages a été transmis aux directeurs de tous les programmes de résidence en médecine d'urgence, offerts en anglais, au Canada, tant ceux du Collège royal des médecins et chirurgiens du Canada (CRMCC [FRCPC]) que ceux du Collège des médecins de famille du Canada (CMFC), compétences avancées (CA). Ont été évalués le nombre de stages obligatoires et optionnels, les exposés magistraux et les examens relatifs aux AVC et aux AIT.

Résultats: Des réponses ont été reçues de 9 programmes du CRMCC (sur 11; taux de réponse [TR] = 82 \%) et de 11 programmes du CMFC (CA) (sur 18; TR =61 \%), ce qui représente 20 programmes sur 29 au Canada (TR:20/29=69\%). Des stages obligatoires en neurologie générale (3/9) et en neurologie des AVC (2/9) étaient offerts dans un petit nombre de programmes du CRMCC et dans aucun programme du CMFC (CA) (0/11). Les stages en neuroradiologie étaient obligatoires dans 1/9 programme du CRMCC et dans aucun programme du CMFC (CA) (0/11). Trois heures d'exposé magistral par année portaient sur les AVC ischémiques aigus dans tous les programmes de résidence, indépendamment du parcours de formation. Malgré le fait que tous les répondants disaient donner de la formation dans des établissements où l'on avait recours à la thrombolyse pour traiter les AVC, les résidents agissaient à titre chefs d'équipe en AVC dans un 1/11 programme (9 \%) seulement du CMFC (CA) et dans 0/9 programme du CRMCC.

Conclusions: La formation officielle, offerte dans les programmes de résidence en médecine d'urgence au Canada sur les AVC et les AIT est minimale. II faudrait accroître les possibilités de formation approfondie puisque que la maladie se manifeste subitement, qu'elle met en danger la vie du malade, qu'elle peut laisser des séquelles invalidantes et même être mortelle, et que le temps influe sur les possibilités de traitement.

Keywords: stroke, transient ischemic attack, medical education, emergency medicine

From the *Department of Emergency Medicine, Kelowna General Hospital, Kelowna, BC; †Department of Emergency Medicine; $\neq$ Division of Neurology, Faculty of Medicine; §Department of Family Practice, University of British Columbia, Vancouver, BC; and ||Department of Emergency Medicine, St. Paul's Hospital, Vancouver, BC.

Correspondence to: Dr. Devin Harris, MD, Department of Emergency Medicine, Kelowna General Hospital, 2268 Pandosy Avenue, Kelowna, BC, V1Y1T2; Email: devin.harris@interiorhealth.ca 


\section{BACKGROUND}

Stroke and transient ischemic attacks (TIA), among other neurological complaints, currently account for $5 \%$ of emergency department (ED) visits. ${ }^{1}$ The treatment of these conditions is time-sensitive, requiring expert and expedited care to prevent morbidity and mortality. ${ }^{2-4}$ Over the last 15 years, diagnostic and therapeutic approaches in the management of acute ischemic stroke have evolved rapidly. Computed tomography (CT) or magnetic resonance imaging (MRI) now allows the skilled physician to quickly and accurately identify subtle signs of stroke and candidates for thrombolysis. ${ }^{5,6}$ Thrombolytic therapies, administered early and appropriately, are known to improve patient morbidity and mortality. ${ }^{7}$ Still, the complexity and variety of presentations of these conditions pose recognized challenges in diagnosis and management among emergency physicians and residents. ${ }^{8-10}$ Educational strategies that focus on emergent evaluation of these common diagnoses may improve diagnostic accuracy, and may result in better patient outcomes by decreasing the time to administration of thrombolytic therapies. ${ }^{11,12}$ With this in mind, we sought to examine the level of clinical and academic stroke training within Canadian emergency medicine programs.

\section{METHODS}

\section{Study design and selection of participants}

A two-page survey was sent by email to residency directors of all 30 English-speaking emergency medicine (EM) residency programs in Canada. This included the 11 Royal College (FRCPC) residency programs (5-year training) and the 19 College of Family Physicians of Canada Enhanced Training [CCFP(EM)] residency programs (3-year training). Residency directors were pre-notified of the need for a survey on this topic prior to distribution, and asked for input. Residency directors were then emailed up to six times over the period of April through September 2011. The survey was distributed as an attachment and respondents returned completed surveys directly to a research assistant. No incentive was provided.

\section{Survey content}

The survey was designed to determine the level of clinical and academic stroke training among Canadian EM residency programs. The survey instrument was generated by the research team, consisting of three emergency physicians (a content expert in stroke; two CCFP(EM) Program Directors) and a stroke neurologist. The survey instrument was pilot tested on emergency physician clinician researchers within the Department of Emergency Medicine, at the University of British Columbia.

Responses were requested regarding the number of residents within each program and the trainee intake into the program for July 2011. From a clinical standpoint, the survey requested information about mandatory and elective rotations in general neurology, stroke neurology, radiology, neuroradiology, and cardiology. Residency directors were asked if their trainees trained in hospitals that administered thrombolysis for acute ischemic stroke, if they did so under emergency physician supervision, and if they were required to lead stroke teams. Academic stroke training questions asked respondents about the total lecture hours per year and, specifically, lecture hours devoted to acute stroke, thrombolysis in acute stroke, and neuroradiology. Residency directors were asked to report total hours of oral examination and how much of this time was devoted to the management of acute ischemic stroke, the use of thrombolytics in acute ischemic stroke, and the management of TIA.

\section{Data analysis}

A descriptive analysis was performed. Means, standard deviations (SDs), and proportions with $95 \%$ confidence intervals (CIs) are reported.

\section{RESULTS}

\section{Program response rates and demographics}

A total of 16 responses were received, representing $20 \mathrm{EM}$ residency programs across Canada (RR: 20/29 $=69 \%$ ). Nine FRCPC programs responded (RR: $9 / 11=82 \%$ ), and $11 \mathrm{CCFP}(\mathrm{EM})$ programs responded (RR: $11 / 18=61 \%$ ). FRCPC programs had an average of 5 new residents per year, with a total of 25 in the program over all five years of residency. $\mathrm{CCFP}(\mathrm{EM})$ programs also accepted an average of five new residents per year, ranging in size from three to nine.

\section{Clinical stroke training (Table 1)}

Despite the fact that $100 \%$ of respondents trained residents in facilities that administered thrombolysis for 
Table 1. Clinical stroke and general neurology training in EM residency programs

\begin{tabular}{llc} 
& FRCPC Programs & CCFP(EM) Programs \\
\hline Mandatory general neurology rotation & $3 / 9(33 \%)$ (mean: 4 weeks) & $0 / 11$ \\
Mandatory stroke neurology rotation & $2 / 9(22 \%)$ (mean: 4 weeks) & $0 / 11$ \\
Electives in neurology & $4 / 9(44 \%)$ (mean: 3.5 weeks) & $1 / 11(9 \%)($ mean: 4 weeks) \\
Mandatory radiology rotation & $1 / 9(11 \%)$ (mean: 4 weeks) & $0 / 11$ \\
Mandatory neuroradiology rotation & $1 / 9(11 \%)$ (mean: 4 weeks) & $0 / 11$ \\
Electives in neuroradiology & $5 / 9(55 \%)$ (mean: 4 weeks) & $3 / 11(27 \%)($ mean: 2.5 weeks) \\
Do residents train in hospitals that administer thrombolytics for stroke? & $9 / 9(100 \%)$ & $11 / 11(100 \%)$ \\
Are residents stroke team leaders? & $0 / 9$ & $1 / 11(9 \%)$
\end{tabular}

Table 2. Didactic stroke training in EM residency programs

\begin{tabular}{lcc} 
& FRCPC Programs & CCFP(EM) Programs \\
\hline Lectures & & $11 / 11(100 \%) 3$ hours \\
Acute stroke lectures (mean hours/year) & $9 / 9(100 \%) 3$ hours & $5 / 11(45 \%) 2.2$ hours \\
Thrombolysis in stroke lectures (mean hours/year) & $8 / 9(88 \%) 2.8$ hours & $6 / 11(54 \%) 2.8$ hours \\
Neuroradiology lectures (mean hours/year) & $8 / 9(88 \%) 3.75$ hours & 180 hours \\
Total lecture hours/year & 170 hours \\
Oral Examinations & $9 / 9(100 \%)$ & $7 / 11(64 \%)$ \\
Acute ischemic stroke & $8 / 9(88 \%)$ & $5 / 11(45 \%)$ \\
Thrombolysis in acute ischemic stroke & $9 / 9(100 \%)$ & $8 / 11(73 \%)$
\end{tabular}

stroke, a minority of programs offered clinical training in stroke. In addition, only 1/11 (9\%) CCFP(EM) programs and 0/9 FRCPC programs had residents act as stroke team leaders.

Mandatory general neurology rotations were present in 3/9 (33\%) FRCPC and 0/11 CCFP(EM) programs. More specific mandatory stroke neurology rotations were offered at 2/9 (22\%) FRCPC and 0/11 CCFP (EM) programs. An option of general or stroke neurology electives were available in 4/9 (44\%) FRCPC programs and 1/11 (9\%) CCFP(EM) programs, with a mean of 3.5 weeks and 4 weeks, respectively. By comparison, 9/9 FRCPC (mean 7 weeks) and 10/11 (91\%) CCFP(EM) (mean 4 weeks) programs have a mandatory cardiology rotation.

Mandatory radiology rotations were present in $1 / 9$ (11\%) FRCPC and 0/11 CCFP(EM) programs. More specific neuroradiology electives were mandatory in $1 / 9$ (11\%) FRCPC programs (mean 4 weeks) and $0 / 11$ CCFP(EM) programs. Electives in either general or neuroradiology were offered to trainees in $5 / 9(55 \%)$ of FRCPC and 3/11 (27\%) CCFP(EM) programs with mean lengths of 4 and 2.5 weeks, respectively.

\section{Academic stroke training (Table 2)}

Acute ischemic stroke was reported as a seminar topic comprising a mean of three lecture hours per year among $100 \%$ of responding programs. All responding FRCPC programs required oral examinations on the treatment and management of acute ischemic stroke and TIA, whereas only 7/11 (64\%) and 8/11 $\mathrm{CCFP}(\mathrm{EM})$ programs required oral examinations on these topics, respectively. Didactic teaching and oral examinations on thrombolysis in acute stroke was reported in 8/9 FRCPC programs and 5/11 CCFP(EM) courses. Neuroradiology lectures occurred in 8/9 FRCPC (mean 3.75 hours) and 6/11 CCFP(EM) (mean 2.8 hours) programs.

\section{DISCUSSION}

Our study highlights that formal stroke education in Canadian emergency medicine residency programs is limited. A minority of residency programs have mandatory clinical rotations in general neurology, stroke neurology, and neuroradiology. The majority of teaching around stroke and TIA is primarily academic, 
in the form of lectures and oral examinations, and yet even that is limited. In addition, there are further disparities in the quantity of training dependent on the route of training.

The proposition "time is brain" highlights the loss of nervous tissue that occurs in ischemic stroke in the absence of emergent evaluation and prompt institution of therapy. The diagnostic challenges faced by emergency physicians and trainees in early identification and management of stroke has been well established. ${ }^{8-10}$ Further, the management of acute TIA is time-sensitive and complex, and without formal training in diagnosis, risk stratification, and management, it represents a significant missed opportunity to prevent stroke., ${ }^{2,13}$ Additionally, misdiagnosing a patient with TIA has significant implications (e.g., patient anxiety, radiation exposure due to imaging, and increased health care costs). Educational strategies that focus on emergent evaluation of these common diagnoses may improve diagnostic accuracy, and may result in better patient outcomes by decreasing the time to administration of thrombolytic therapies, or by the application of proven therapies after a TIA to prevent stroke. ${ }^{11.12}$ As such, a larger emphasis on clinical stroke training during residency is warranted, as only a minority of residency programs are offering mandatory clinical rotations in general neurology, stroke neurology, and neuroradiology, with even fewer offering such rotations electively. As a solution, both the $\mathrm{CCFP}(\mathrm{EM})$ and FRCPC programs should provide more mandatory training in stroke for residents, through participation in stroke prevention clinics, in stroke units, and in the ED as stroke team leaders. Recognizing that the largest barrier to stroke training is the limited time within residency programs, it is imperative that emergency physicians are well trained for a such a time-sensitive and significant disorder as stroke. In contrast, almost all emergency medicine residency programs had mandatory rotations in cardiology with, at minimum, four weeks of training.

Our study highlights that the predominant mode of formal stroke training in Canadian emergency medicine programs is academic, using a combination of lecture and oral examinations. Only $1 \%$ of lecture time was devoted to stroke and TIA within the emergency medicine residency programs, despite neurologic emergencies being $5 \%$ of all presenting complaints to EDs. With the rapidly evolving nature of the stroke field, and its significant morbidity and mortality, it may be beneficial to emergency residents to have a larger portion of academic time devoted to stroke evaluation and management. In addition, as simulation is incorporated more into emergency training, it is imperative to expose residents to simulated stroke scenarios during residency.

Informal stroke training does occur during emergency medicine rotations. ${ }^{14}$ It is in this format that emergency medicine preceptors likely provide the majority of stroke training for emergency medicine residents. However, in larger centres, where many emergency medicine residents are trained, stroke teams and neurology services often provide much of the emergent care, leaving emergency medicine trainees out of the thrombolysis decision-making process.

\section{LIMITATIONS}

As with any survey, there are multiple sources of bias that may influence the results and conclusions. Our survey was conducted in English; therefore, this survey reflects only the training that is provided in the nonFrancophone programs. Only five of 30 programs are French-speaking; this was not expected to introduce significant bias, as similar training is reported between English-speaking and Francophone programs. ${ }^{15}$ In addition, this was an email survey; this may have contributed to a lower response rate despite the targeted and frequent contacts.

\section{CONCLUSION}

Currently, formal training in stroke and TIA in Canadian emergency medicine residency programs is limited. The most common method of training is through academic lectures. Only a limited number of Canadian emergency residency programs offer either mandatory or elective clinical rotations in stroke neurology and neuroradiology. As emergency medicine takes on more responsibility in the acute management of stroke and TIA, it is paramount that future emergency physicians have adequate training during residency. Enhanced training opportunities during residency and as fellowships should be implemented.

Competing Interests: Dr. Harris: Bayer (consulting), Pfizer (consulting), ESD Stroke Rehabilitation Inc. (Director); Dr. Teal: SanofiAventis (consulting, lecture), Bristol-Myers Squibb (consulting, lecture), Boehringer Ingelheim (consulting, lecture), Bayer (consulting). No other conflict of interests declared. 
This paper was presented at the Canadian Association of Emergency Physicians Annual General Meeting, Vancouver, BC, June 2013.

\section{REFERENCES}

1. National Hospital Ambulatory Medical Care Survey: 2010 emergency department summary tables. Available at: http:// www.cdc.gov/nchs/data/ahcd/ nhamcs_emergency/2010_ed_ web_tables.pdf (accessed June 1, 2014).

2. Rothwell PM, Warlow CP. Timing of TIAs preceding stroke: time window for prevention is very short. Neurology 2005;64(5):817-20.

3. Saver JL. Time is brain - quantified. Stroke 2006;37:263-6.

4. Harraf F, Sharma AK, Brown MM, et al. A multicentre observational study of presentation and early assessment of acute stroke. BMf 2002;325(7354):17.

5. Schriger DL, Kalafut M, Starkman S, et al. Cranial computed tomography interpretation in acute stroke: physician accuracy in determining eligibility for thrombolytic therapy. FAMA 1998;279(16):1293-7.

6. Canadian Agency for Drugs and Technologies in Health. Appropriateness of CT imaging to support the diagnosis of stroke: a review of the clinical evidence. Available at: http:// www.cadth.ca/en/products/rapid-response/publication/4057 (accessed June 1, 2014).

7. Lees KR, Von Kummer R, Bluhmki E, et al. Time to treatment with intravenous alteplase and outcome in stroke: an updated pooled analysis of ECASS, ATLANTIS, NINDS, and EPITHET trials. Lancet 2010;375(9727):1695-703.

8. Pope JV, Edlow JA. Avoiding misdiagnosis in patients with neurological emergencies. Emerg Med Int 2012;2012:949275. doi:10.1155/2012/949275.

9. Newman-Toker DE, Robinson KA, Edlow JA. Frontline misdiagnosis of cerebrovascular events in the era of modern neuroimaging: a systematic review. Ann Neurol 2008;64(12): S17-S8.

10. Morgenstern LB, Lisabeth LD, Mecozzi AC, et al. A population-based study of acute stroke and TIA diagnosis. Neurology 2004;62(6):895-900.

11. Moeller JJ, Kurniwan J, Gubitz GJ, et al. Diagnostic accuracy of neurological problems in the emergency department. Can 7 Neurol Sci 2008;35(3):335-41.

12. Hansen CK, Fisher J, Joyce N, et al. Emergency department consultations for patients with neurological emergencies. Eur 7 Neurol 2011;18(11):1317-22.

13. Schrock JW, Glasenapp M, Victor A, et al. Variables associated with discordance between emergency physician and neurologist diagnoses of transient ischemic attacks in the emergency department. Ann Emerg Med 2012;59(1):19-26.

14. Stettler BA, Jauch EC, Kissela B, et al. Neurologic education in emergency medicine training programs. Acad Emerg Med 2005;12(9):909-11.

15. Canadian Resident Matching Service. 2015 Family Medicine/Emergency Medicine Match Program Descriptions. Available at: http://www.carms.ca/en/residency/fmem/programdescriptions/archive/ (accessed June 2015). 